\title{
The DARWIN Breadboard Optical Delay Line Verification Programme
}

\author{
T. C. van den $\operatorname{Dool}^{\mathrm{a}}(*)$, F. Kamphues ${ }^{\mathrm{a}}$, W. Gielesen ${ }^{\mathrm{a}}$, \\ J. Benoit ${ }^{\mathrm{b}}$, E. Laurenceau ${ }^{\mathrm{b}}$, A. Poupinet ${ }^{\mathrm{c}}$ F. Sève ${ }^{\mathrm{c}}$, Y. Stockman $^{\mathrm{d}}$, K. Fleury ${ }^{\mathrm{d}}$,

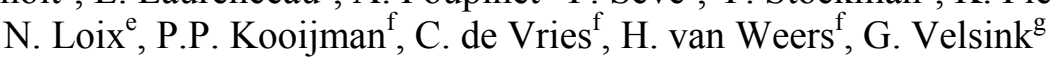 \\ ${ }^{\mathrm{a}} \mathrm{TNO}$, Stieltjesweg 1, $2628 \mathrm{CK}$, Delft, THE NETHERLANDS \\ ${ }^{\mathrm{b}}$ Alcatel Alenia Space, Bld. du Midi, F-06156 Cannes La Bocca, FRANCE \\ 'Sageis-CSO, 70, Avenue des Martyrs, 38000 Grenoble, FRANCE \\ ${ }^{\mathrm{d}}$ Centre Spatiale de Liege (CSL), Parc Scientifique du Sart Tilman, Angleur (Liège), BELGIUM \\ ${ }^{\mathrm{e}}$ Micromega-Dynamics, Rue des Chasseurs Ardennais, B-4031, Angleur (Liège), BELGIUM

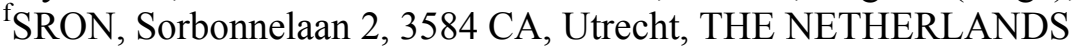 \\ ${ }^{\mathrm{g}}$ Dutch Space, Newtonweg 1, 2333 CP, Leiden, THE NETHERLANDS
}

\begin{abstract}
TNO, in co-operation with Micromega-Dynamics, SRON, Dutch Space and CSL, has designed a compact breadboard cryogenic delay line (figure 1) for use in future space interferometry missions. The breadboard (BB) delay line is representative of a flight mechanism. The delay line has a single stage voice coil actuator for Optical Path Difference (OPD) control, driving a two-mirror cat's eye. Magnetic bearings provide frictionless and wear free operation with zerohysteresis. The development test programme, including operation at $100 \mathrm{~K}$ has been completed. The verification test programme is currently being carried out by Alcatel Alenia Space (in co-operation with Sageis-CSO) and will include functional testing at $40 \mathrm{~K}$. A short design description and the intermediate results of the verification test programme are reported in this paper.
\end{abstract}

Keywords: optical delay line, verification programme, ODL, cryogenic, DARWIN, TPF-I, PEGASE, active magnetic bearings, nano positioning, aperture synthesis, nulling interferometry

\section{INTRODUCTION}

The DARWIN Optical Delay Line (ODL) will play an important role in ESA's DARWIN Infrared Nulling Interferometer [1]. The delay line has to equalise and fine-tune the optical path length differences between the telescopes in the interferometer constellation. The optical path lengths must be equalised at sub nanometer level without introducing significant wave front errors, beam tilt or lateral beam deviation. The delay lines will also be used for fringe scanning, after course acquisition of the telescope constellation. The delay lines will be placed on the optical bench in the Hub spacecraft and will operate at $40 \mathrm{~K}$ [2]. Within this study, the responsibilities for the design and development are divided as follows:

- $\quad$ TNO - Project management, systems engineering, optical design and OPD control

- Micromega-Dynamics - Guiding system development

- $\quad$ SRON - Actuator and power amplifier development and cryogenic consultancy

- $\quad$ Centre Spatiale de Liege - Coating engineering and 40K TV facility

- $\quad$ Dutch Space - Thermal modelling and development tests at $100 \mathrm{~K}$

- Alcatel Alenia Space - Mission level consultancy and verification test programme (in co-operation with Sageis-CSO)

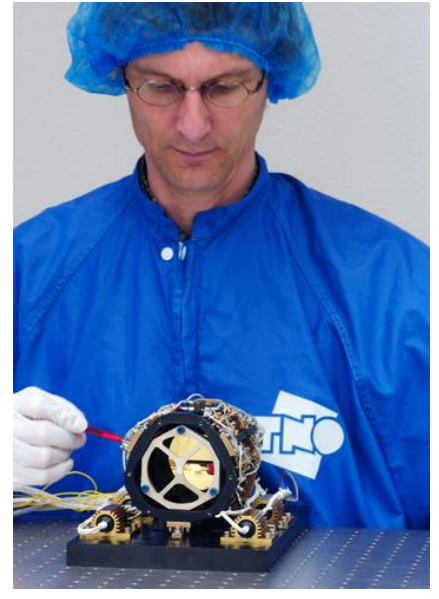

Figure 1 - DARWIN Optical Delay Line

(*) teun.vandendool@tno.nl; phone 31-15-26 92 457; fax 31-15-26 92 111; www.tno.nl/space 


\section{DESIGN DESCRIPTION}

The DARWIN ODL program includes the development and delivery of a dynamic delay line and a static (non-moving) delay line (figure 1 and figure 2). The dynamic delay line consists of four main elements [3]:

- Two-mirror Cat's Eye

- Magnetic Bearing (MB) guiding system

- Voice Coil OPD actuator and amplifier

- $\quad \mathrm{OPD}$ and MB controller and electronics

The ODL is designed for operation in a temperature range of $40-300 \mathrm{~K}$. The cat's eye structure and mirrors are constructed from Al 6061. This makes the design fully athermal. Differential thermal bending is minimised by the application of Alumiplate ${ }^{\circledR}$ on the Aluminium mirrors. Both materials have virtually the same CTE. Alumiplate can be diamond turned to a very low surface roughness, and requires no additional polishing. The mirrors are manufactured by TNO and coated by CSL (figure 7 and 8 ). The achieved surface roughness is around $2-3 \mathrm{~nm}$ RMS and the wave front error of the M1 was less than $60 \mathrm{~nm}$ p-v over the full aperture of $61 \mathrm{~mm}$.

Magnetic bearings were chosen for the guiding system, because they offer a number of benefits over conventional guiding systems, such as ball bearings and flexures:

- Have virtually zero friction and zero hysteresis

- Require no lubrication

- Are non-contact and wear free

- The inherent cleanliness makes them highly suitable for sensitive optical instruments

- Mechanical alignment errors can be corrected with active bearing control

If pupil imaging is not required for DARWIN, a corner cube type retro reflector could also be used, still using the same magnetic bearing guiding technology.

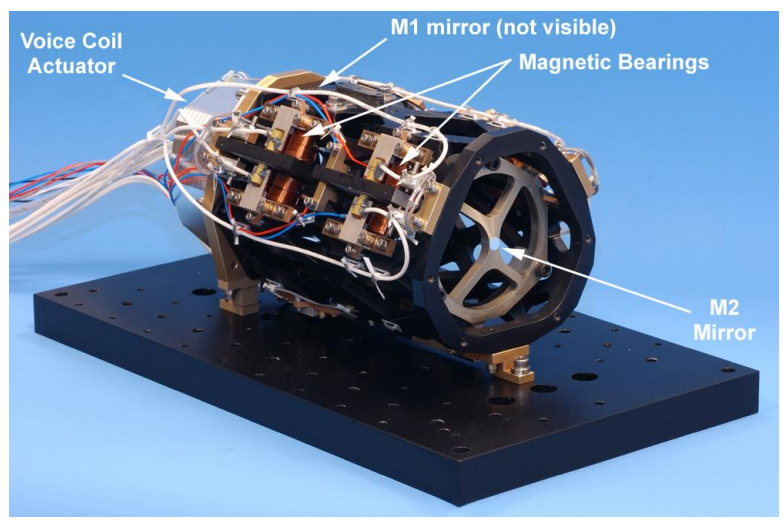

Figure 2 - Dynamic ODL

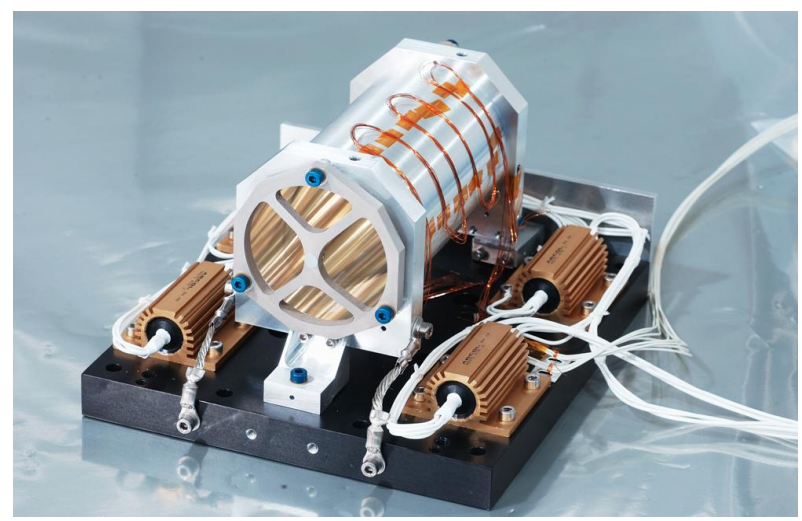

Figure 3 - Static ODL

(with heaters on baseplate for thermal control during vacuum test)

The ODL magnetic bearing system was developed by Micromega-Dynamics, using their recent experience with the MABE mechanism [5]. The ODL magnetic bearing is equipped with a 1-g magnetic off loading device, to enable ground testing in horizontal position.

The measured power overall dissipation of the five magnetic bearing is less than $2.5 \mathrm{~mW}$ at room temperature. At $40 \mathrm{~K}$ the power dissipation will be around $20 \mathrm{~mW}$, mainly as the result of heat leak through the wires. For the flight models, special cryogenic cable will be used, which will reduce the power dissipation to approximately $2 \mathrm{~mW}$.

A total of five fully redundant magnetic bearings constrain 5 degrees of freedom. 
The OPD voice coil actuator (also fully redundant) controls the remaining degree of freedom. The voice coil actuator and the amplifier electronics were developed by SRON. The design of the actuator is based on proven hardware, used for the ISO and HIFI missions (both for a cryogenic environment).

The voice coil actuator is located at the back of the cat's eye. Since the actuator magnet is mounted on the back of the mirror, an intermediate flexure structure was developed, in order to minimise the thermal strains in the mirror caused by the different CTE's of magnet and mirror (figure 4). The coil is attached to the static part of the ODL and the magnet is attached to the moving part, thus preventing disturbance forces caused by electrical wires and heat dissipation in the optical (moving) part of the ODL.

For reasons of redundancy, the voice coil consists of two concentric coils, an inner and an outer one. An ultra low noise current amplifier with a large dynamic range powers the voice coil.
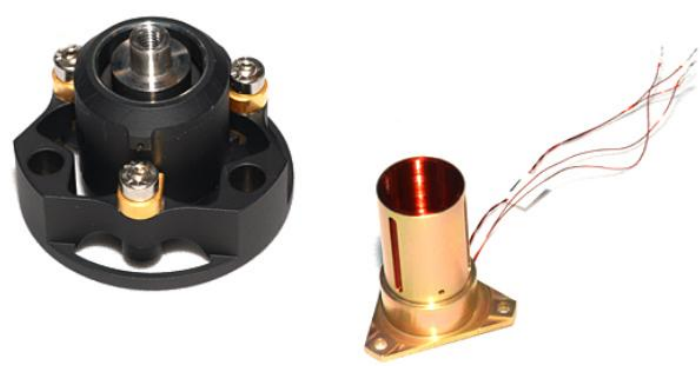

Figure 4 - Voice coil assembly (magnet on the left, coil on the right)

The DARWIN BB ODL uses a digital controller. The magnetic bearings and OPD actuator run on one single controller. The controller has been implemented on a real-time Linux PC and programmed from a Matlab/Simulink environment, to enable quick adjustment and fine-tuning of control parameters during the development phase.

For the DARWIN mission, the control algorithm will be implemented in a low power digital processor. SRON is currently developing an FPGA based low power controller board, which will meet the ESA target for power consumption.

The OPD sensor (Fringe Sensor in DARWIN) is simulated by a laser metrology system with sub nanometer resolution. This allows testing with a high control bandwidth, to cope with the high disturbance spectrum during ground testing.

A comprehensive development tests programme was carried out in 2005, including deep thermal cycling of components and assemblies and operation of the ODL at $100 \mathrm{~K}$ in vacuum [6].

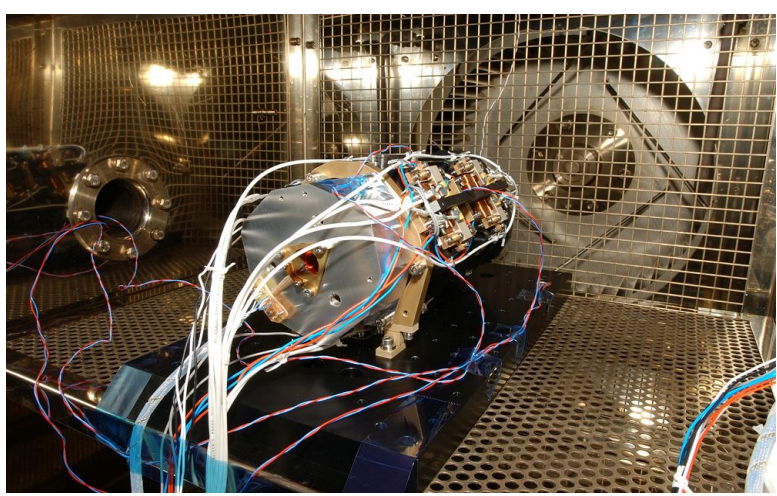

Figure 5 - Thermal cycling at Dutch Space

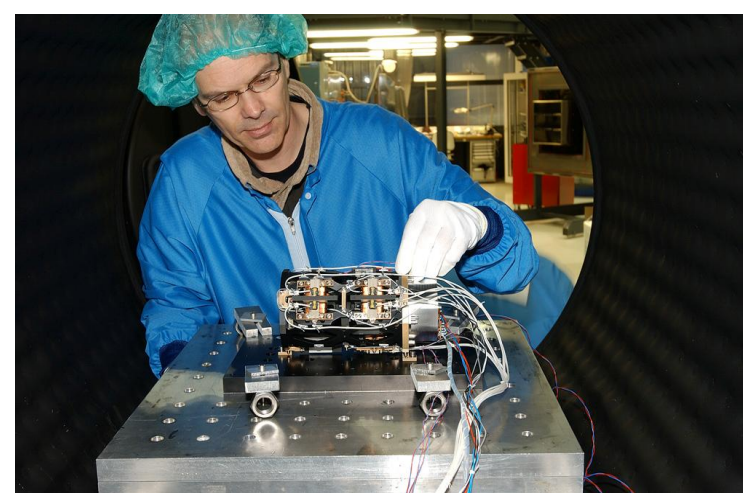

Figure 6 - Thermal vacuum test at Dutch Space 


\section{VERIFICATION PROGRAMME}

Alcatel Alenia Space, in co-operation with Sageis-CSO, is currently carrying out the verification test programme at ODL assembly level. It comprises an ambient test programme and a cryogenic test programme at $40 \mathrm{~K}$.

The ambient test programme is done in a class 100 clean room at Sageis-CSO in Grenoble.

The $40 \mathrm{~K}$ test programme will take place in the Focal 2 facility at the Centre Spatial de Liège (CSL), after completion of the ambient test programme.

\subsection{Verification test matrix}

The verification test matrix is shown in the table below:

\begin{tabular}{|c|c|c|c|}
\hline $\mathbf{N}^{\circ}$ & Measurements & Tests environment & Tested item \\
\hline \multicolumn{4}{|c|}{ ODL general requirements } \\
\hline 1. & ODL power dissipation & Ambient $+40 \mathrm{~K}$ & Dynamic ODL \\
\hline 2. & Micro vibrations environment & Ambient $+40 \mathrm{~K}$ & Dynamic ODL \\
\hline \multicolumn{4}{|c|}{ ODL optical requirements } \\
\hline 3. & Beam tilt & Ambient $+40 \mathrm{~K}$ & Dynamic ODL \\
\hline 4. & Beam lateral deviation & Ambient $+40 \mathrm{~K}$ & Dynamic ODL \\
\hline 5. & Wave front distortion & Ambient $+40 \mathrm{~K}$ & $\begin{array}{l}\text { Dynamic ODL } \\
\left.\text { Static ODL }{ }^{*}\right)\end{array}$ \\
\hline 6. & Optical transmission losses & Ambient $+40 \mathrm{~K}$ & Dynamic ODL \\
\hline 7. & Relative polarisation & Ambient & $\begin{array}{l}\text { Dynamic ODL } \\
\text { Static ODL }\end{array}$ \\
\hline 8. & $\begin{array}{l}\text { Polarisation variation (over the full } \\
\text { actuation range) }\end{array}$ & Ambient & Dynamic ODL \\
\hline \multicolumn{4}{|c|}{ ODL functional and dynamic requirements } \\
\hline 9. & ODL stroke & Ambient $+40 \mathrm{~K}$ & Dynamic ODL \\
\hline 10. & ODL resolution & Ambient $+40 \mathrm{~K}$ & Dynamic ODL \\
\hline 11. & ODL stability & Ambient $+40 \mathrm{~K}$ & Dynamic ODL \\
\hline 12. & Fringe scanning profiles & Ambient $+40 \mathrm{~K}$ & Dynamic ODL \\
\hline 13. & Following of OPD variation & Ambient $+40 \mathrm{~K}$ & Dynamic ODL \\
\hline 14. & Maximum ODL rate & Ambient $+40 \mathrm{~K}$ & Dynamic ODL \\
\hline 15. & Settling time (in closed loop) & Ambient $+40 \mathrm{~K}$ & Dynamic ODL \\
\hline 16. & Overshoot & Ambient $+40 \mathrm{~K}$ & Dynamic ODL \\
\hline 17. & Mass & Ambient & $\begin{array}{l}\text { Dynamic ODL } \\
\text { Static ODL }\end{array}$ \\
\hline 18. & Dimensions & Ambient & Dynamic ODL \\
\hline
\end{tabular}

(*) WFE on Dynamic ODL will be measured at $40 \mathrm{~K}$, Static ODL only before and after cryogenic test

Verification of the optical coating requirements of the mirrors was also done at sample level by CSL. The coating tests included the following measurements:

- Mirror surface roughness

- Coating adhesion before and after thermal cycling

- Optical transmission

- Relative spectral response

- Chromatic phase differences

- Relative polarisation rotation

- Relative polarisation ellipticity 


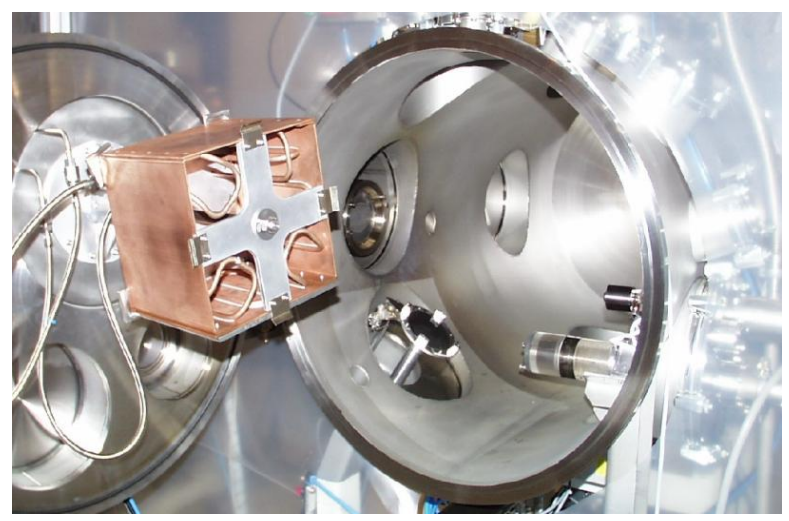

Figure 7 - Ion beam sputtering coating facility at CSL

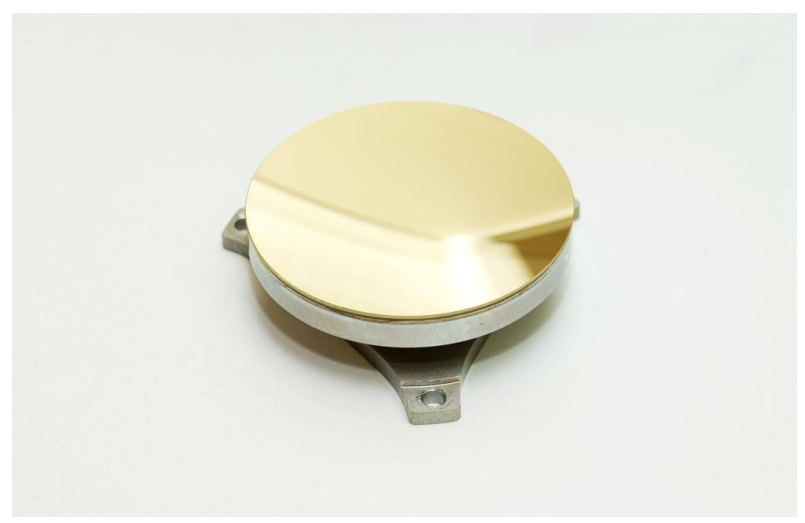

Figure 8 - M1 mirror with reflective Gold coating

\subsection{General test set-up}

Sageis-CSO developed a specific optical bench to test and qualify the ODL (figure 9). The test bench is divided in two parts:

- A fixed part that contains the laser and the interferometer, which are not only used for verification, but also to drive the ODL

- A mobile part that contains various optical instruments. It allows 3 main configurations :

- Shack-Hartmann sensor for Wave Front Error (WFE) measurements

- Electronic autocollimator for relative tilt variation measurements over the actuation range.

- Special optical head for lateral deviation, optical transmission, and polarisation measurements

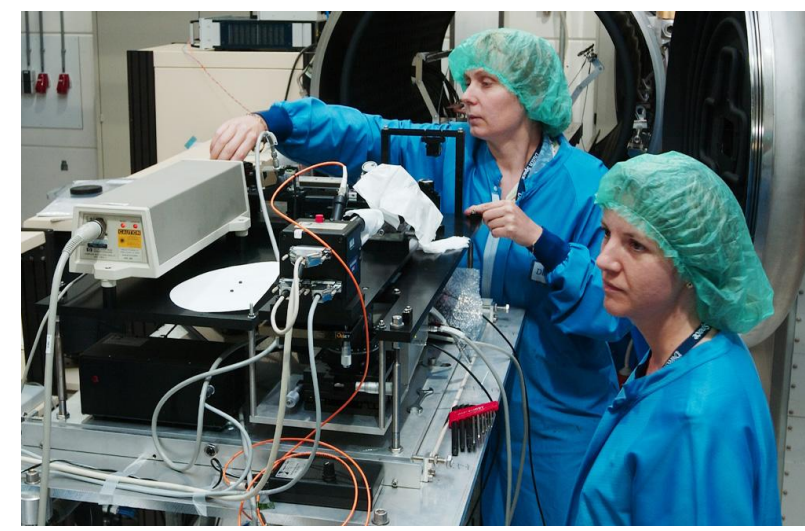

Figure 9 - ODL optical test bench

During measurements, the ODL is driven by a test bench PC and specific software (Labview). This application is driving the ODL through the ODL control PC (Linux environment) and the test equipment (figure 10).

The ODL tests are performed fully automatically with scripts through the specific software. These scripts command automatically the ODL displacement and the controllers of the test equipment. No manual acquisition is done during the test procedure. 


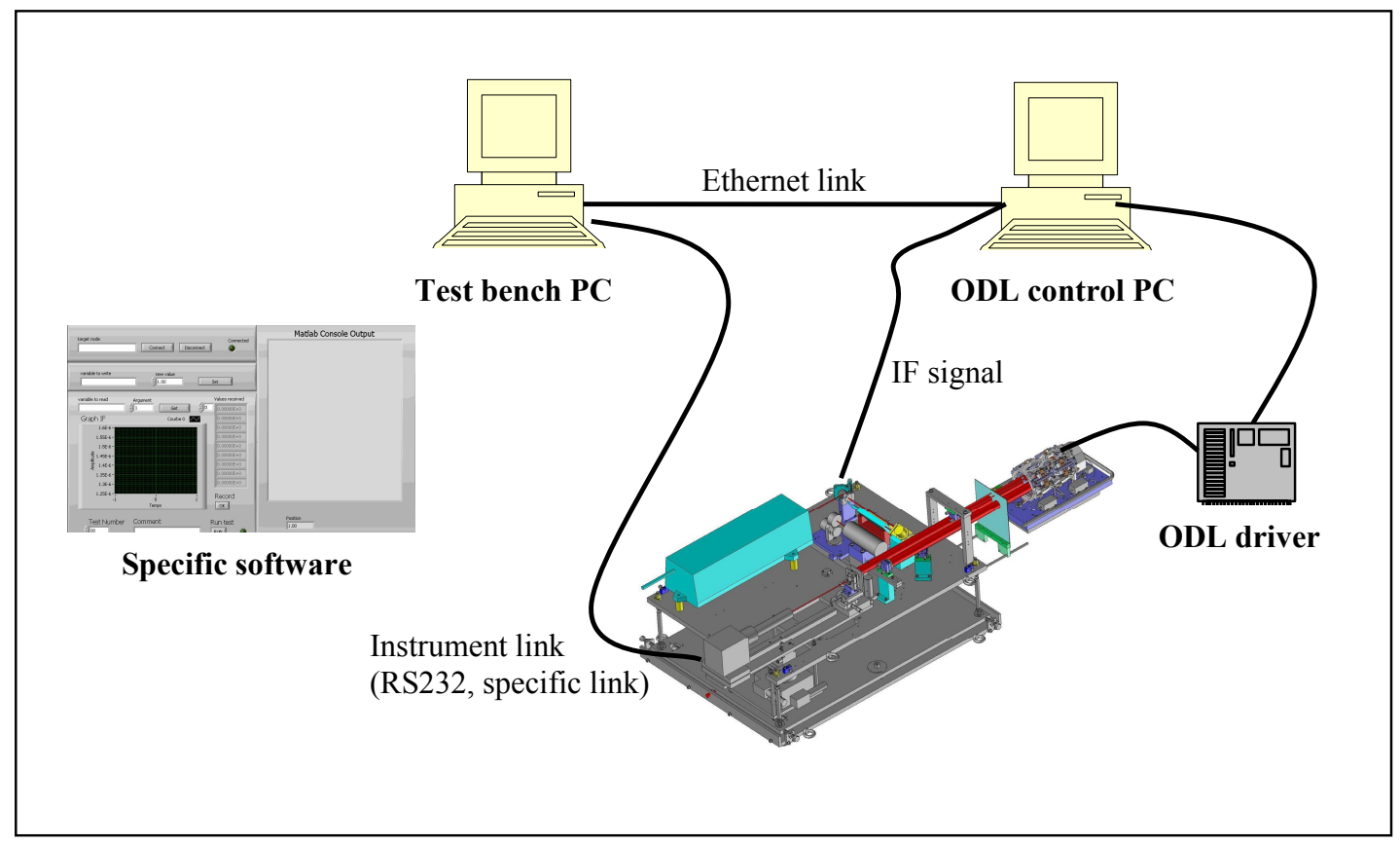

Figure 10 - Automated test set-up

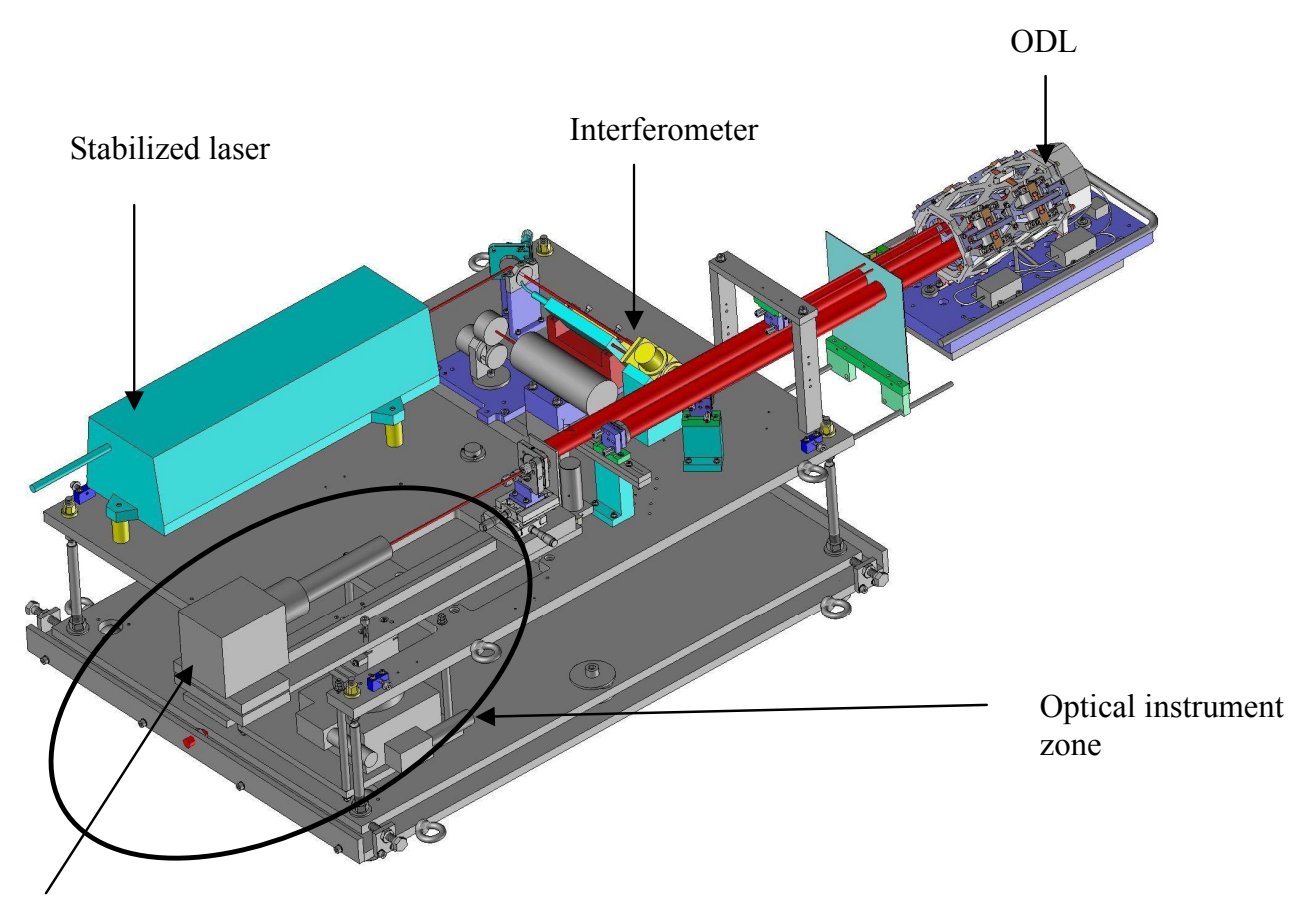

WFE analyser

Figure 11 - ODL optical test bench in WFE measurement configuration 


\subsection{WFE measurements}

In WFE measurement configuration, the test bench is equipped with a HASO Shack-Hartmann WFE analyser in double pass configuration (figure 11). The HASO system is combined with a collimator, allowing the acquisition of the WFE map over a $25 \mathrm{~mm}$ pupil in real time, with a very high sample rate (acquisition time of $200 \mu \mathrm{sec}$ ). The WFE is checked for various positions on the ODL stroke. The Zernike tilt coefficient is removed from the measurements.

The measurement accuracy is $8 \mathrm{~nm}$ RMS over an aperture of $25 \mathrm{~mm}$.

\subsection{Tilt measurements}

Tilt measurements are done with a Moeller Wedel electronic autocollimator, used in double pass configuration. A precision of 0.02 arcsec is reached on the measurement of the relative tilt variation over the full actuation stroke of the ODL. The bench with the autocollimator is shown in figure 12 .

Tilt measurements are done, while the ODL is scanning over the whole stroke back and forth. By synchronising acquisition and time filtering, external vibration can be removed from the acquisition signal. The ODL tilt variation is then calculated over the full stroke by $1 \mathrm{~mm}$ stroke averaging.

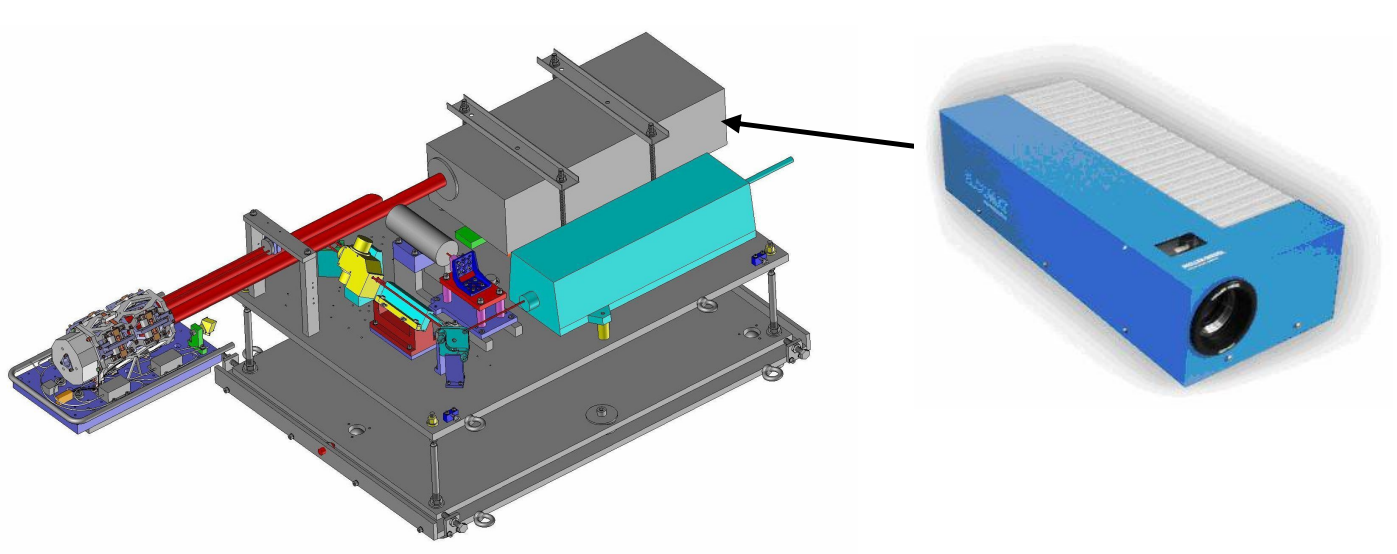

Figure 12 - Tilt measurement set-up

\subsection{Optical decentre (lateral deviation), optical transmission and polarisation measurement}

A special optical head has been developed for various measurements: optical decentre (lateral deviation), optical transmission and polarisation measurement (figure 13).

The detection unit is changed, depending on the measurement performed. The detection unit can be either:

- A photo detector for transmission measurement

- A PSD (Position sensitive detector) for lateral deviation system

- A polarisation detector which gives the stokes parameters (S0, S1, S2 and S3) of the optical beam 


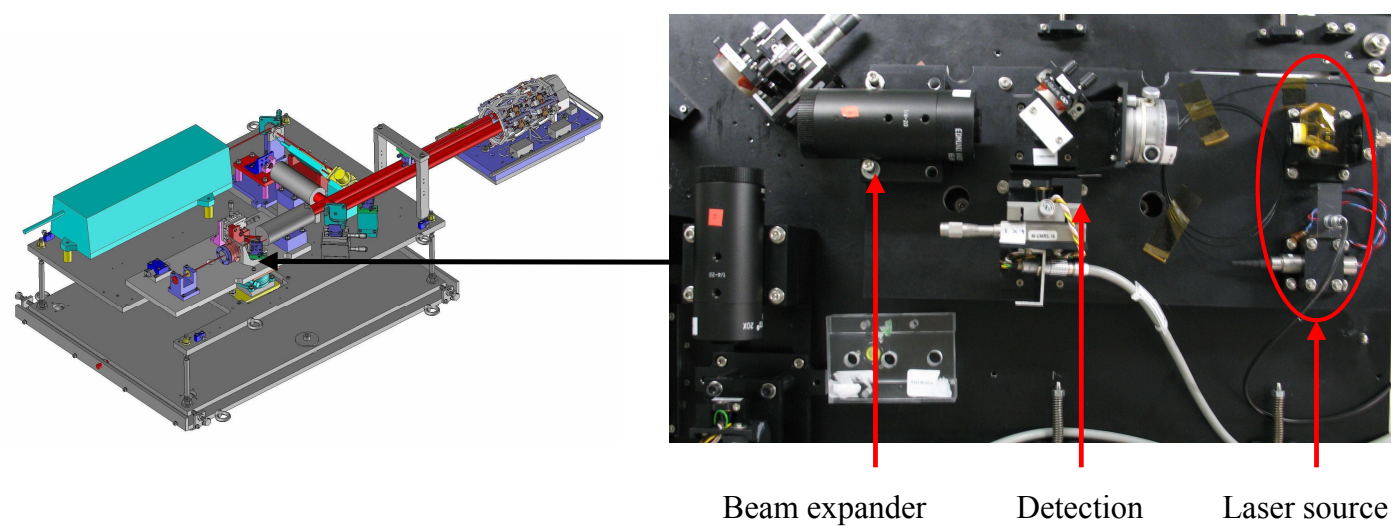

Figure 13 - Optical decentre, optical transmission and polarisation measurement set-up

\subsection{Cryogenic test set-up}

The ODL verification test campaign is completed with a cryogenic test, during which the Dynamic ODL performance is tested in the DARWIN operational environment at 40K.

Both dynamic and optical performance is tested. As a consequence, the test bench is integrated outside the Thermal Vacuum (TV) facility to give access for adjustment and configuration changes of the test bench. Optical performance measurements are done through a high optical quality window. The window was characterised by Sageis-CSO. Window wave front errors will be subtracted from the ODL WFE.

The Static ODL is only subjected to the cryogenic environment. No measurements are made on the Static ODL during the TV test, but the WFE is measured before and after the test.

The thermal design of the test set-up is designed by Alcatel Alenia Space. Thermal modelling of the ODL was done by Dutch Space.

Both optical delay lines (dynamic and static) are located inside the TV facility (see figure 14). They are fully encircled with a radiative tent ( 6 assembled square panels), fed with liquid Helium at $20 \mathrm{~K}$.

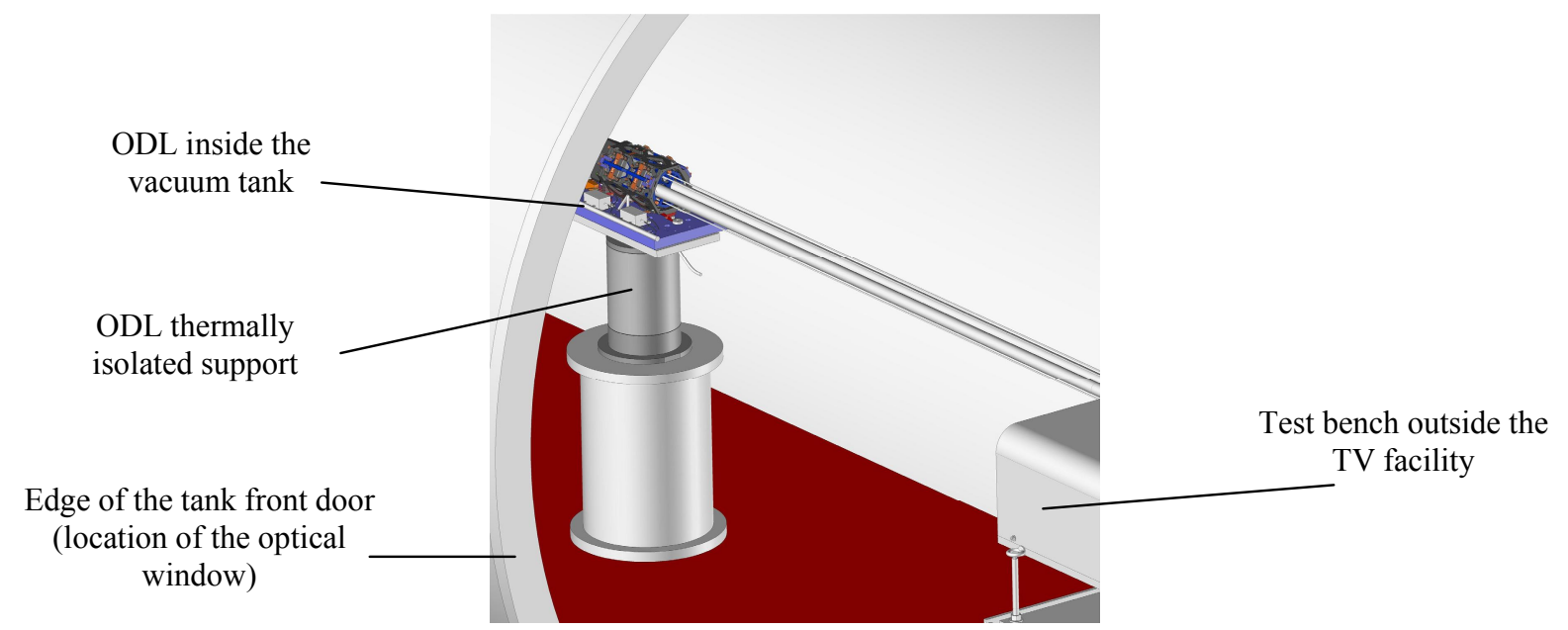

Figure 14 - ODL cryogenic set-up inside the thermal vacuum tank and test bench outside 
The ODLs are cooled down to $40 \mathrm{~K}$ radiatively (with the panels) and conductively with a Helium pipe, surrounding the baseplate of the ODL (see figure 15). Thermal straps make the conductive link from the pipe to the Aluminum baseplates supporting the two ODLs.

The baseplates are isolated from the "warm" ground at 300K thanks to isolating stages (Permaglass washers and Quartz tube), in order to avoid thermal leaks.

Thermal heaters are integrated on the baseplates to control the thermal cooling speed, ensure thermal uniformity (gradient minimisation) and allow quick heating-up at the end of the test.

The thermal design ensures the whole test campaign will be run at the Darwin operational temperature of $40 \mathrm{~K}$.

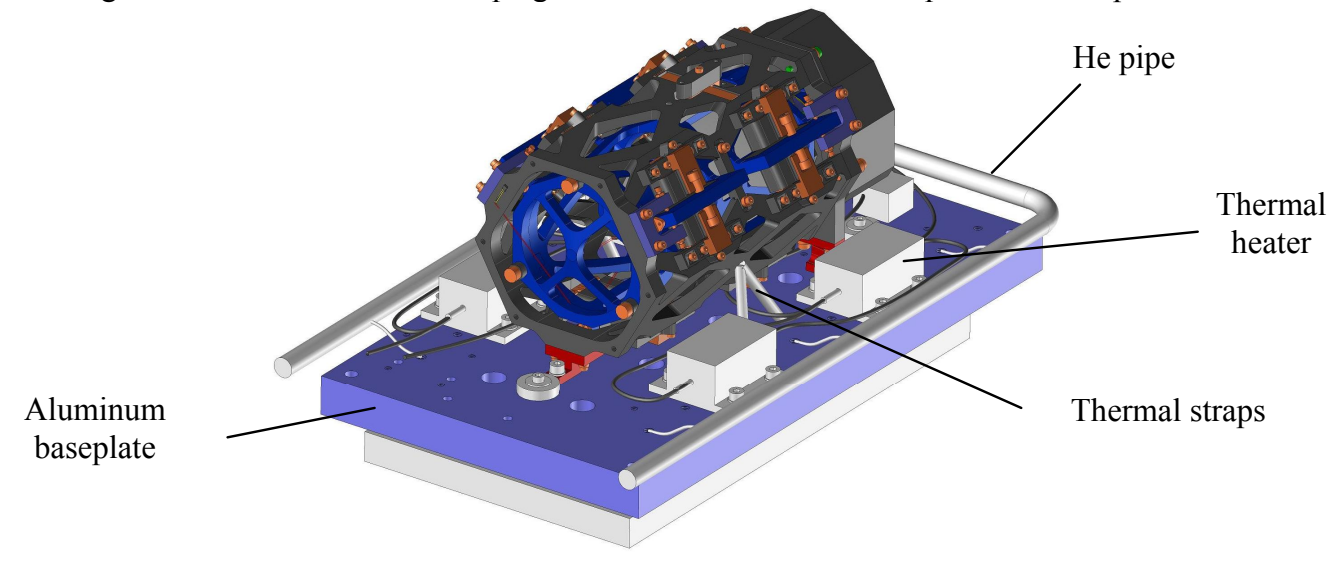

Figure 15 - Cryogenic set-up with dynamic ODL cooled with He-pipe and conductive Aluminum baseplate

\section{PERFORMANCE}

The measured OPD error in the TNO laboratory was better than $0.9 \mathrm{~nm}$ RMS, with an open loop disturbance spectrum of $2103 \mathrm{~nm}$ RMS (figure 16). A high-speed laser metrology system was used for OPD control. Based on these measurements, it has been calculated that an OPD error of better than $1 \mathrm{~nm}$ can be achieved in the DARWIN spacecraft environment, when the fringe sensor sample rate is higher than $100 \mathrm{~Hz}$.

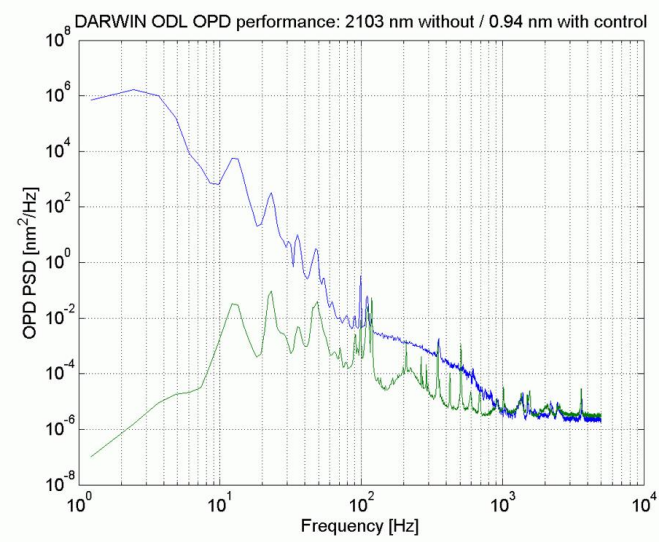

Figure 16 - Optical Path stability of delay line 
The verification test programme includes Wave Front Error (WFE) measurements at ambient temperature and at $40 \mathrm{~K}$. The WFE measurement at ambient temperature for the left and right hand apertures is shown in figure 17. The total WFE is $12 \mathrm{~nm}$ RMS (vs. required $<32 \mathrm{~nm}$ ), allowing some margin for cool down to $40 \mathrm{~K}$.
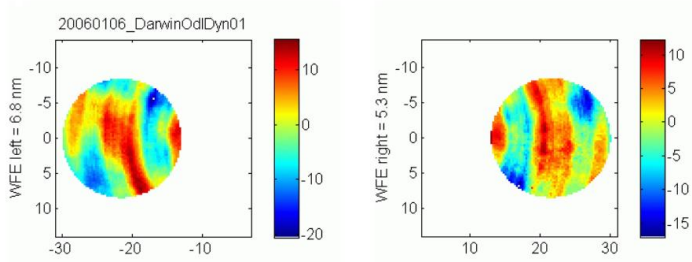

Figure 17 - Wave Front Error of Cat's Eye

The variation of the output beam tilt over the full stroke has been measured to be $0.02 \operatorname{arcsec}(0.1 \mu \mathrm{rad}) \mathrm{p}-\mathrm{v}$, limited by the accuracy of the test set-up (figure 18). A cross check measurement of the tilt of the cat's eye revealed that the output beam tilt variation is probably less than $0.1 \mu \mathrm{rad}$.

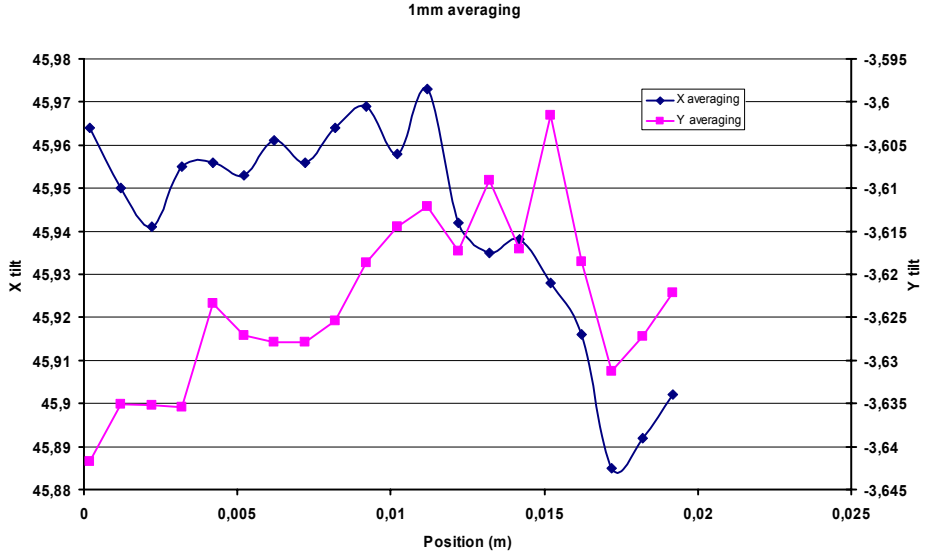

Figure 18 - Dynamic beam tilt measurements

The lateral deviation measurement is shown in figure 19. 500 measurements, with a step of 100 ms, were taken with the ODL scanning. The measured lateral deviation was less than $10 \mu \mathrm{m}$ per axis (p-p), which is the noise level of the sensor. This is well below the specification of maximum $100 \mu \mathrm{m}$ decentre.

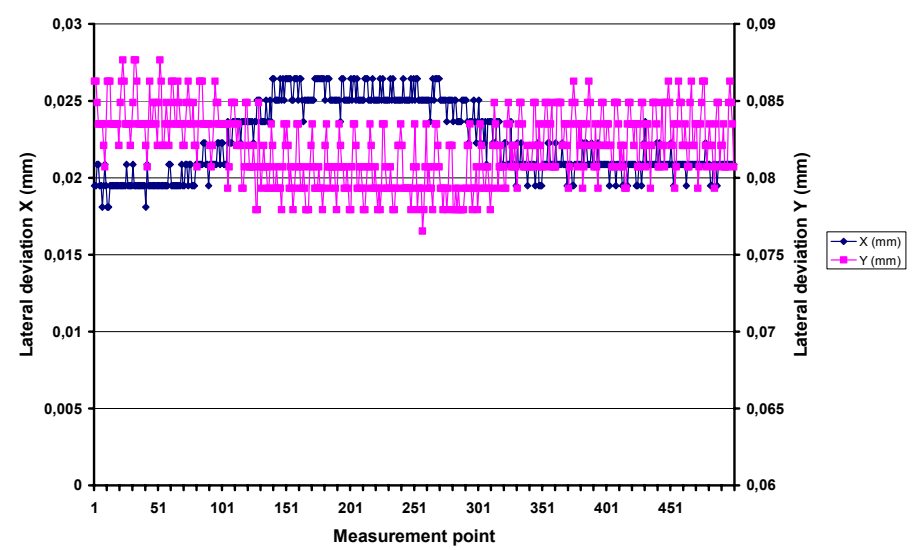

Figure 19 - Lateral deviation measurement 
A summary of other measured parameters measured in the verification test programme is given in the table below. Performance parameters at $40 \mathrm{~K}$ have not yet been measured.

\begin{tabular}{|c|c|c|}
\hline & Requirement & Measured \\
\hline $\begin{array}{cc}\text { ODL power consumption } \\
- & \text { at } 40 \mathrm{~K} \text { in space } \\
- & \text { at } 40 \mathrm{~K} \text { on ground }\end{array}$ & $<25 \mathrm{~mW}$ & $\begin{array}{l}\text { Expected: } \\
\sim 2 \mathrm{~mW} \text { (flight models) } \\
\sim 20 \mathrm{~mW} \text { (in breadboard) }\end{array}$ \\
\hline Dynamic output beam tilt & $<0.24 \mu \mathrm{rad}$ & $\begin{array}{l}<0.1 \mu \mathrm{rad} \\
\text { (limited by test set-up accuracy) }\end{array}$ \\
\hline Output beam lateral deviation & $<100 \mu \mathrm{m}$ & $\begin{array}{l}<10 \mu \mathrm{m} \text { per axis } \\
\text { (limited by test set-up accuracy) }\end{array}$ \\
\hline Total RMS wave front distortion & $<32 \mathrm{~nm}$ & $\begin{array}{l}12 \mathrm{~nm} \text { at } \mathrm{RT} \\
<32 \mathrm{~nm} \text { at } 40 \mathrm{~K} \text { (expected) }\end{array}$ \\
\hline Mirror surface roughness & - & $\sim 2 \mathrm{~nm}$ RMS \\
\hline $\begin{array}{cc}\text { Optical transmission losses } \\
\text { - } & \text { from } 0.65 \text { to } 4 \mu \mathrm{m} \\
- & \text { from } 4 \text { to } 20 \mu \mathrm{m}\end{array}$ & $\begin{array}{l}<15 \% \\
<6 \%\end{array}$ & $\begin{array}{l}<15 \% \\
<3 \%\end{array}$ \\
\hline Relative spectral response & $<1 \mathrm{e}-4$ & $\begin{array}{l}0.90 \mathrm{e}-4 @ 450-850 \mathrm{~nm} \\
0.35 \mathrm{e}-4 @ 2-20 \mu \mathrm{m}\end{array}$ \\
\hline $\begin{array}{c}\text { Chromatic phase differences } \\
-\quad \text { for } \lambda<1 \mu \mathrm{m} \\
-\quad \text { for } \lambda>1 \mu \mathrm{m}\end{array}$ & $\begin{array}{l}<0.1 \mathrm{~nm} \text { RMS } \\
<\lambda / 10000 \mathrm{RMS}\end{array}$ & $\begin{array}{l}<0.01 \mathrm{~nm} \\
<\lambda / 13500 \mathrm{RMS} @ \lambda=4 \mu \mathrm{m}\end{array}$ \\
\hline Relative polarisation rotation & $<0.1^{\circ}$ & $<0.0002^{\circ}$ \\
\hline Relative polarisation ellipticity & $<0.1^{\circ}$ & $<0.001^{\circ}$ \\
\hline Static beam tip/tilt & $<14.5 \mu \mathrm{rad}$ & $<4 \mu \mathrm{rad}$ \\
\hline $\begin{array}{cl}\text { OPD } & \\
- & \text { range (optical) } \\
- & \text { resolution } \\
- & \text { stability }\end{array}$ & $\begin{array}{l}>20 \mathrm{~mm} \\
<0.5 \mathrm{~nm} \\
<1 \mathrm{~nm}\end{array}$ & $\begin{array}{l}20.4 \mathrm{~mm} \\
0.3 \mathrm{~nm} \text { (limited by test set-up accuracy) } \\
0.9 \mathrm{~nm} \\
\text { (with TNO lab disturbance spectrum) }\end{array}$ \\
\hline $\begin{array}{cl}\text { Dynamic } & \text { response } \\
- & \text { ODL rate } \\
- & \text { Settling time } \\
- & \text { Damping }\end{array}$ & $\begin{array}{l}>250 \mu \mathrm{m} / \mathrm{s} \\
<20 \mathrm{~ms} \\
>0.9\end{array}$ & $\begin{array}{l}>20 \mathrm{~mm} / \mathrm{s} \\
<20 \mathrm{~ms} \\
>0.9\end{array}$ \\
\hline $\begin{array}{l}\text { Dimensions } \\
\text { (including } 0 \text {-g offloading device) }\end{array}$ & $115 \times 115 \times 300$ & $\begin{array}{l}114 \times 116 \times 210 \\
\text { (excluding launch lock) }\end{array}$ \\
\hline Mass & $<10 \mathrm{~kg}($ target $<6 \mathrm{~kg})$ & $\begin{array}{l}1.7 \mathrm{~kg} \\
(<4 \mathrm{~kg} \text { expected including cable harness } \\
\text { and flight electronics })\end{array}$ \\
\hline Design lifetime & 10 years & $>10$ years \\
\hline
\end{tabular}

\section{FUTURE ACTIVITIES}

The current OPD/Magnetic Bearing (MB) controller runs on a real time Linux based PC, in order to have maximum flexibility with respect to control algorithms. The power dissipation of this controller is not representative for the future DARWIN controller. A conventional DSP based control board dissipates in the order of $15 \mathrm{~W}$ and would not meet the $2.5 \mathrm{~W}$ overall power dissipation requirement. TNO and SRON are currently developing a low power $(<2 \mathrm{~W})$ FPGA based control board for combined OPD and MB control.

A launch lock is not part of the current development program, but will be required for a future mission.

Furthermore, TNO recommends to verify the optical alignment under zero-g conditions (e.g. parabolic flight).

After the successful completion of the verification program, TNO is looking for a flight opportunity in a future space interferometer or technology demonstrator mission (e.g. the proposed PEGASE mission). Please contact Ben Braam at TNO, if you wish to discuss this (ben.braam@tno.nl).

TNO is also offering a slightly modified version of this ODL for the ESA GENIE instrument on the ESO VLTI telescopes. This delay line technology can also be used in other ground based astronomical instruments. 


\section{CONCLUSIONS}

TNO and its partners have demonstrated that extremely accurate path length control is possible with the use of magnetic bearings and a single stage actuation concept. Active magnetic bearings are contactless, have no friction or hysteresis and are wear free. Further verification testing will be done under cryogenic conditions later this year.

\section{AKNOWLEDGEMENTS}

The work is performed under ESA contract 17.747/03, with support from the Netherlands's Agency for Aerospace Programs (NIVR), in preparation for the DARWIN mission. TNO would like to thank Josep Maria Perdigues Armengol (ESA-ESTEC), Joost Carpay (NIVR), and Gustavo Vallejo (Alumiplate) for their support during the development of the delay line.

\section{REFERENCES}

1. DARWIN-The InfraRed Space Interferometer, Concept and Feasibility Study Report", Version 1.2 ESA-SCI(2002)12, April 2002.

2. Statement of Work, Optical Delay Lines, Programme Reference: TRP, ID-OP-12 TOS-MMO/2002/276, issue 2.0, 6 March 2003.+ clarifications 1, 2 and 3.

3. T.C. van den Dool et al, 'The design of a breadboard Cryogenic Optical Delay Line for DARWIN', SPIE Conference Astronomical Telescopes and Instrumentation Vol. 5495-40, June 2004, Glasgow, United Kingdom.

4. 'Active Vibration Control for an Optical Delay Line', N.J. Doelman, T.C. van den Dool. Proc. of Active 2002, pp.887898

5. MABE, Fine Precision Mechanism Based on Magnetic Bearing Technology, Micromega Dynamics - Executive Summary (ESA Contract No 13676/99/NL/PA)

6. T.C. van den Dool et al, 'The manufacturing, assembly and acceptance testing of the breadboard Cryogenic Optical Delay Line for DARWIN', SPIE Conference Optics and Photonics, Vol. 5904-367, August 2005, San Diego, USA 